\title{
The influence of storage method on the transparency of pig crystalline lens
}

\section{A influência do método de armazenamento na transparência do cristalino de porco}

\author{
Cristina Artigas', Adriana Fandiño², Amparo Navea², María M López-Murcia', Francisco Bosch-Morell', \\ Rafael Araujo-Miranda², José M. Artigas ${ }^{3}$ \\ 1. Faculty of Veterinary. University Cardenal Herrera, Valencia, Spain. \\ 2. Fisabio Oftalmología Médica, Valencia, Spain. \\ 3. Departament of Optics, Faculty of Physics, University of Valencia, Valencia, Spain.
}

\begin{abstract}
Purpose: The porcine eye is frequently used as a research model. This paper analyzes the effect of different storage methods on the transparency of pig crystalline lens. Methods: A spectral transmission curve (from 220 to $780 \mathrm{~nm}$ ) for the crystalline lens was determined experimentally after storage in different conditions: saline solution, formalin, castor oil, and freezing at $-80^{\circ} \mathrm{C}$. The total transmission in the visible spectrum, which was used as an index of transparency, was calculated from these curves. For comparative purposes, fresh lenses were evaluated and used as controls. Results: Storing the porcine crystalline lens in saline solution or castor oil resulted in a transparency loss of approximately $10 \%$ after $24 \mathrm{~h}$ and storage in formalin resulted in a loss of nearly $30 \%$. Storage by freezing at $-80^{\circ} \mathrm{C}$ for 4 weeks maintained the transparency of the crystalline lens; the spectral transmission measured immediately after defrosting at room temperature coincided exactly with that of the freshly extracted lens. Conclusions: The transparency of porcine crystalline lens is affected by the storage method. The visible spectrum is the most affected, evidenced by the effect on the transparency and consequently the amount of light transmitted. The results show that freezing at $-80^{\circ} \mathrm{C}$ maintains the transparency of the crystalline lens for at least 4 weeks.
\end{abstract}

Keywords: Lens, crystalline; Organ preservation; Freezing; Animals; Swine

RESUMO | Objetivos: Olho de porco é frequentemente usado como modelos de pesquisa. Este estudo analisa o efeito de

Submitted for publication: March 22, 2017

Accepted for publication: June 3, 2018

Funding: No specific financial support was available for this study.

Disclosure of potential conflicts of interest: None of the authors have any potential conflicts of interest to disclose.

Corresponding author: Jose M. Artigas

Departamento de Óptica - Facultad de Física - Universidad de Valencia

C/Dr Moliner, 50 - E46100-Burjassot - Valencia - Spain - E-mail: Jose.Artigas@uv.es diferentes métodos de armazenamento na preservação da transparência do cristalino de porco. Métodos: Uma curva de transmissão espectral (de 220 até $780 \mathrm{~nm}$ ) para o cristalino foi experimentalmente determinada após armazenamento em diferentes condições: solução salina, formol, óleo de mamona e congelamento a $-80^{\circ} \mathrm{C}$. Transmissão total do espectro visível, que foi usada como um índice de transparência foi calculada a partir dessas curvas. Para fins comparativos, lentes frescas foram avaliadas e usadas como controles. Resultados: O armazenamento do cristalino suíno em solução salina ou óleo de mamona resultou uma perda de transparência de aproximadamente $10 \%$ após $24 \mathrm{~h}$ e o armazenamento em formol resultou uma perda de quase $30 \%$. O armazenamento por congelamento a $-80^{\circ} \mathrm{C}$ durante 4 semanas manteve a transparência do cristalino; a transmissão espectral medida imediatamente após o descongelamento à temperatura ambiente coincidiu exatamente com a da lente extraída recentemente. Conclusão: A transparência do cristalino suíno é afetada pelo método de armazenamento. O espectro visível é o mais afetado, evidenciado pelo efeito sobre a transparência e consequentemente a quantidade de luz transmitida. Os resultados mostram que o congelamento a $-80^{\circ} \mathrm{C}$ mantém a transparência do cristalino suíno por pelo menos 4 semanas.

Descritores: Cristalino; Preservação de órgãos; Congelamento; Animais; Suínos

\section{INTRODUCTION}

In studies of both human and animal ex vivo crystalline lenses, transparency is one of the most frequently investigated optical properties as it is related to cataracts, the capacity to filter ultraviolet (UV) radiation, and aging of the crystalline lens in general. The most accurate method of analyzing lens transparency is by determining the spectral transmission ${ }^{(1)}$. 
Nonetheless, it is often impossible to perform measurements immediately after extraction, so the problem of storage arises. Some studies ${ }^{(2-4)}$ reported that the post-mortem human crystalline lens stored in castor oil at $4^{\circ} \mathrm{C}$ can maintain its transmissivity for several weeks. However, one of the studies ${ }^{(2)}$ was conducted to demonstrate that both the capacity of the crystalline lens for forming images and its transmissivity in the visible part of the spectrum remain more or less unaltered for a long time, regardless of the metabolic changes that occur post-mortem. To this end, the author experimentally determined the optical density for four wavelengths $(381,405,469$, and $595 \mathrm{~nm}$ ) and reported that in order to establish a link between metabolism and optical performance, re-examination would be required.

We used pig eyes in our study to ensure a large and uniform sample of crystalline lenses. Porcine eyes have been used as a research model for several decades. As a result, many studies have been performed on them ${ }^{(5-8)}$, particularly studies on the action of UV radiation on pig crystalline lens, which is particularly important in crystalline lens transmission ${ }^{(9-11)}$.

Here, we evaluated different methods of storing crystalline lens ex vivo to ascertain whether they affect or alter transparency. We analyzed transparency by experimentally determining the spectral transmission of the samples using the transmission curve measured with a spectrophotometer, which covers both the visible and UV spectra. We calculated the loss of total light that can occur in the visible range from these data, thus obtaining a transparency value.

\section{METHODS}

\section{Pig lens}

In our experiments, we used the crystalline lenses of freshly slaughtered common pigs from an industrial abattoir for meat production. The pigs were slaughtered at 6 months of age. The eyes were removed during slaughter, stowed in suitable containers in a saline solution, and sent to our laboratory 5 or $6 \mathrm{~h}$ afterwards where the lenses were removed. All the eyes we used belonged to genetically similar pigs fed the same diet and slaughtered at the same age; thus, our study was made up of a sample of homogeneous lenses.

Particular care was taken during lens removal when detaching the crystalline lenses from the zonules to avoid damaging the capsules. The crystalline lenses were placed in specifically designed lens holders so that they could be measured with a UV/VIS spectrometer.

\section{Storage method}

Freshly extracted porcine crystalline lenses were stored immediately in saline solution, $(\mathrm{NaCl} 0.9 \% \mathrm{~B}$. Braun, Melsungen AG, Germany), formalin (buffered formalin 4\%, QCA, Spain), or castor oil (Sigma 259953) for $24 \mathrm{~h}$ at room temperature. After this period, spectral transmission was measured and compared with the mean transmission of the freshly extracted crystalline lens. In each case, three crystalline lenses were used and were stored in different containers to confirm the repeatability. For the frozen samples, freshly extracted crystalline lenses were frozen immediately at $-80^{\circ} \mathrm{C}$, which was the storage temperature. The defrosting process was natural, i.e., at room temperature. The spectral transmissions of freshly defrosted crystalline lens were measured at $30 \mathrm{~min}$ and $1 \mathrm{~h}$ after defrosting. Three crystalline lenses were also used for this condition.

\section{Spectral transmission measurements}

For spectral transmission measurement, we used a method described in previous studies ${ }^{(1,12-15)}$. The transmission curves were obtained using a Perkin-Elmer Lambda 35 UV/VIS spectrometer (Perkin-Elmer Inc., Shelton, CT, USA) (Figure 1A). This apparatus can measure the spectrum from $200 \mathrm{~nm}$ onwards, which means that spectral transmissions in ultraviolet A (UVA), ultraviolet B (UVB), and part of ultraviolet C (UVC) are accurately determined (precision is up to $1 \mathrm{~nm}$ ). Air was used as the reference to measure transmittance. The measurements were for the total transmission of the crystalline lens, so the apparatus was equipped with an integrating sphere. A suitable lens holder (Figure 1B) was designed and constructed to keep the sample (crystalline lens) directly in front and cover the complete entrance hole of the integrating sphere of the spectrophotometer (Figure 1C).

\section{Calculation of the transmission}

The total transmission of the crystalline lens in the visible spectrum can be calculated from the spectral transmission curves, and this provides a measurement of their transparency ${ }^{(16)}$.

To determine the total transmission of the visible spectrum for a crystalline lens, we first calculated the tristimulus values $(X, Y, Z)$ using the following formulas: 

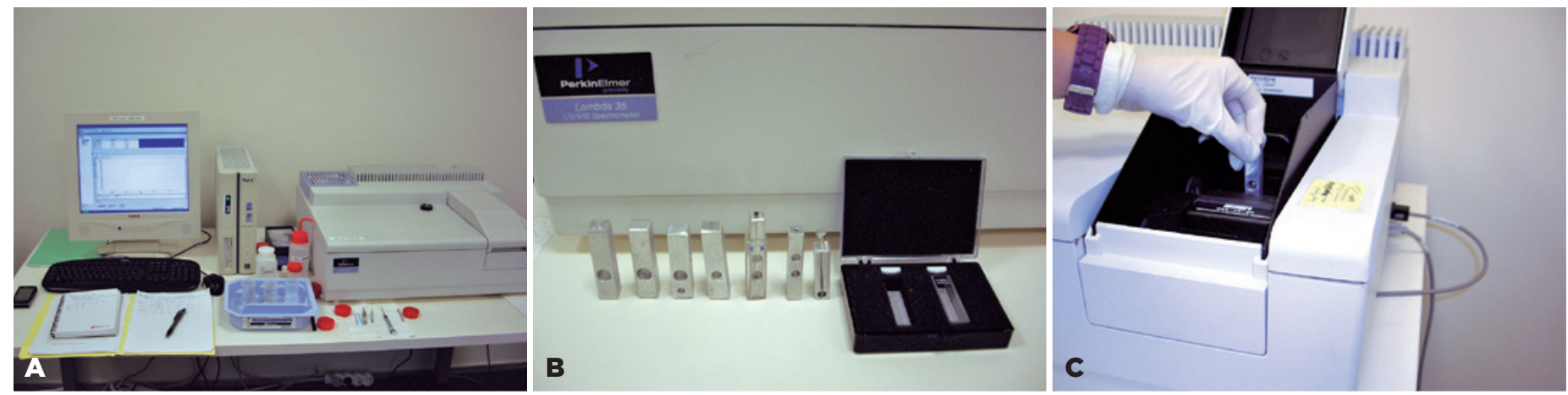

Figure 1. A) Spectrophotometer Perkin Elmer Lambda 35 UV/VIS used in this experiment. B) Different lens holders designed and built especially for placing the sample in the spectrophotometer. The three holders on the left are the holders for the pig lenses. C) Placement of lens holder with the crystalline lens directly in front and covering the complete entrance hole of the integrating sphere of the spectrophotometer.

$$
\begin{aligned}
X & =\sum_{\lambda} \bar{x}(\lambda) S(\lambda) \tau(\lambda) \\
Y & =\sum_{\lambda} \bar{y}(\lambda) S(\lambda) \tau(\lambda) \\
Z & =\sum_{\lambda} \bar{z}(\lambda) S(\lambda) \tau(\lambda)
\end{aligned}
$$

where $\bar{x}(\lambda), \bar{y}(\lambda), \bar{z}(\lambda)$ are the color matching functions of the standard observer, $S(\lambda)$ is the spectral distribution of the source (in our case, illuminant D65 or solar illumination) and $\tau(\lambda)$ is the spectral transmittance of the crystalline lens. The value of the tristimulus $\mathrm{Y}$ indicates the lightness or luminance of the surface color and the transmittance of the filter in our case (crystalline lens). We calculated the total transmission $(T)$ in the visible spectrum using the following formula:

$$
T=\frac{\sum_{\lambda} \bar{y}(\lambda) S(\lambda) \tau(\lambda)}{\sum_{i} \bar{y}(\lambda) S(\lambda)}
$$

Differences with $\mathrm{p}<0.05$ were considered significant. Results are expressed as the mean and standard deviation.

\section{RESULTS}

\section{Baseline}

We measured the transmission of 12 randomly selected porcine crystalline lenses to establish the baseline. The Kolmogorov-Smirnov test confirmed that the variable follows a normal distribution ( $p>0.50$ for any wavelength). Table 1 shows the transmission values for eight wavelengths for the 12 crystalline lenses as well as their mean, standard deviation, and the confidence interval for 12 and 3 lenses at 90\% confidence. As the standard deviations were small for all wavelengths $(\lambda)$, we investigated whether three measurements would be sufficient to establish a transmission curve. There was no significant difference between the 12 and 3 measurements and the significance $p$ was $>0.30$ was for all $\lambda$ in the curve. In view of these results, we felt that measuring three crystalline lenses was sufficient for reliable determination in our study. All the curves shown in this report represent the mean of three crystalline lenses. Figure 2 shows the transmission curve for the common pig crystalline lens with the confidence interval.

\section{Storage in saline solution}

Figure 3 compares the spectral transmission of the pig crystalline lens according to the storage method. This figure shows the mean spectral transmission curve for the freshly extracted porcine crystalline lenses and the mean curve for these same crystalline lenses after storage in saline solution for $24 \mathrm{~h}$. After this period, transmission undergoes a decrease, particularly in the visible spectrum range. If equations (1) and (2) are applied, this loss of light transmission (transparency) can be quantified at about $10 \%$, because a freshly extracted lens presents on average 94\% transmission in the visible spectrum. After $24 \mathrm{~h}$ in saline solution, this transmission drops to $83 \%$.

\section{Storage in formalin}

The mean spectral transmission curve for the porcine crystalline lens kept in formalin $24 \mathrm{~h}$ after extraction is shown in Figure 3 compared with that of the freshly extracted crystalline lens. As can be seen in this figure, the lens transmission undergoes a general decrease after 24 $\mathrm{h}$ in formalin, which is greater for shorter wavelengths. Equations (1) and (2) indicate that this loss of trans- 
Table 1. Spectral transmission for eight wavelengths for the 12 pig crystalline lenses measured. Standard deviation (SD). Confidence interval for 12 lenses, $\mathrm{Cl}$ (12), at $90 \%$ confidence. Confidence interval for three lenses, $\mathrm{Cl}(3)$, at $90 \%$ confidence

\begin{tabular}{|c|c|c|c|c|c|c|c|c|}
\hline Wavelength (nm) & 350 & 400 & 450 & 500 & 550 & 600 & 650 & 700 \\
\hline Lens 1 & 13.06 & 6.96 & 87.87 & 9.55 & 94.91 & 96.04 & 96.90 & 97.30 \\
\hline Lens 2 & 14.38 & 65.68 & 86.37 & 91.29 & 93.71 & 9.88 & 9.80 & 96.22 \\
\hline Lens 3 & 13.60 & 61.72 & 81.75 & 86.20 & 88.79 & 89.75 & 90.65 & 91.01 \\
\hline Lens 4 & 17.09 & 65.76 & 86.41 & 91.13 & 93.19 & 94.21 & 95.02 & 95.46 \\
\hline Lens 5 & 18.82 & 67.41 & 85.61 & 89.70 & 91.88 & 92.75 & 93.60 & 94.14 \\
\hline Lens 6 & 15.72 & 63.97 & 83.22 & 87.22 & 89.57 & 90.18 & 90.96 & 91.41 \\
\hline Lens 7 & 18.54 & 68.49 & 88.48 & 92.58 & 94.89 & 95.80 & 96.65 & 97.16 \\
\hline Lens 8 & 11.01 & 60.56 & 83.42 & 88.04 & 90.37 & 91.32 & 92.10 & 92.57 \\
\hline Lens 9 & 12.90 & 64.68 & 87.10 & 92.16 & 94.08 & 96.04 & 96.91 & 97.47 \\
\hline Lens 10 & 18.24 & 63.74 & 82.51 & 86.49 & 88.73 & 89.76 & 90.53 & 91.14 \\
\hline Lens 11 & 17.03 & 67.47 & 85.81 & 89.82 & 92.55 & 92.60 & 93.77 & 94.56 \\
\hline Lens 12 & 19.92 & 64.47 & 87.29 & 91.48 & 93.08 & 94.24 & 95.01 & 95.34 \\
\hline MEAN & 15.83 & 64.91 & 85.49 & 89.89 & 92.21 & 93.13 & 93.99 & 94.48 \\
\hline SD & 2.85 & 2.31 & 2.23 & 2.36 & 2.33 & 2.43 & 2.44 & 2.43 \\
\hline $\mathrm{Cl}(12)$ & 1.35 & 1.09 & 1.05 & 1.12 & 1.10 & 1.15 & 1.16 & 1.16 \\
\hline $\mathrm{Cl}(3)$ & 2.53 & 2.78 & 2.37 & 2.41 & 2.15 & 2.16 & 2.12 & 2.17 \\
\hline
\end{tabular}

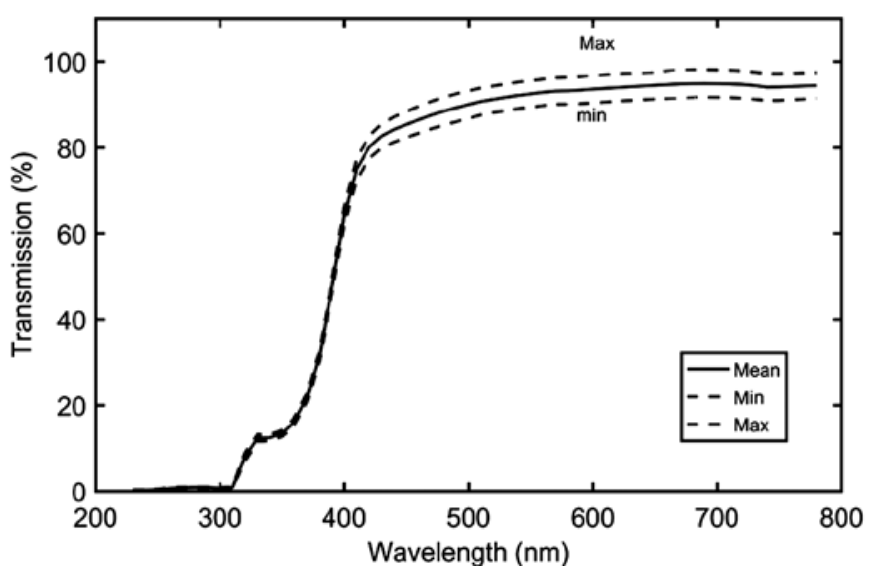

Figure 2. Mean of the transmission curve for the pig lens (three lenses) with a confidence interval of $90 \%$.

parency is almost $30 \%$. The crystalline lens goes from $94 \%$ transmission in the visible spectrum when freshly extracted to $68 \%$ transmission after $24 \mathrm{~h}$ in formalin.

\section{Storage in castor oil}

The mean spectral transmission of porcine crystalline lenses stored in castor oil for $24 \mathrm{~h}$ after extraction is shown in Figure 3 compared with the mean transmission of the freshly extracted crystalline lens. The result is similar to that obtained after storage in saline solution. There is a decrease of approximately $10 \%$ in the total transmission of visible light, from $94 \%$ trans-

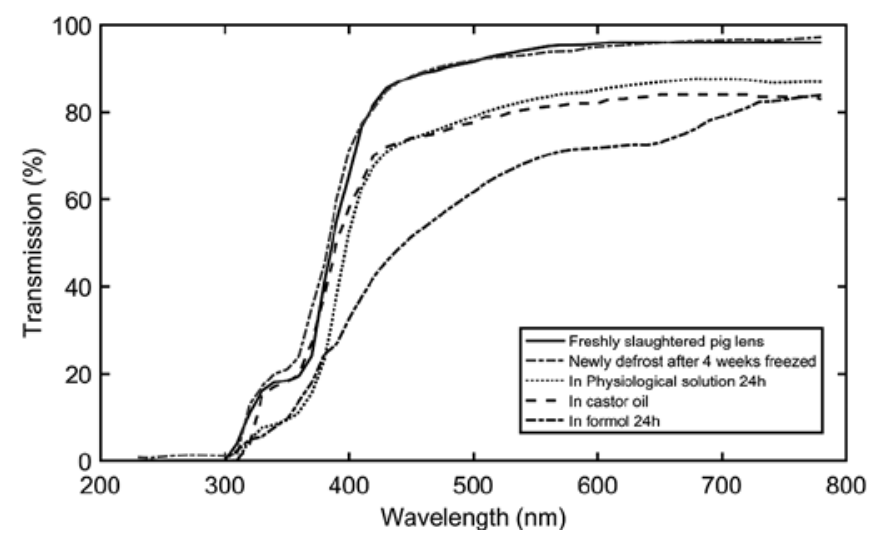

Figure 3. Comparison of the spectral transmissions of the pig lens depending on the storage method.

mission in the freshly extracted crystalline lens to $81 \%$ after $24 \mathrm{~h}$ in castor oil.

\section{Storage by freezing}

The final storage method used in this study was freezing. The spectral transmission of the porcine crystalline lens after freezing at $-80^{\circ} \mathrm{C}$ for 4 weeks followed by defrosting at room temperature is shown in Figure 3 compared with the mean transmission of the freshly extracted crystalline lens. Figure 4 shows the spectral transmissions of the freshly defrosted crystalline lens at $30 \mathrm{~min}$ and $1 \mathrm{~h}$ after defrosting, compared with the spectral transmission of the freshly extracted crystalline lens. 


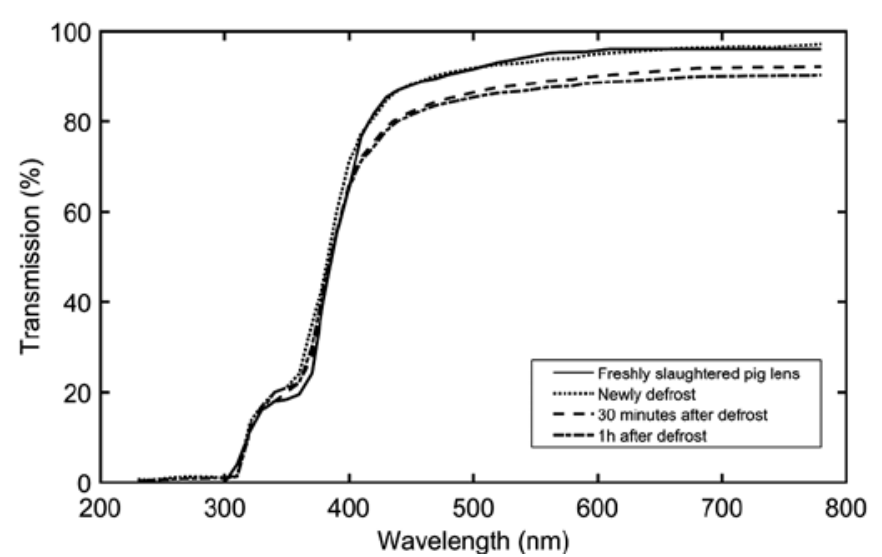

Figure 4. Mean spectral transmission of pig lenses after freezing at $-80^{\circ} \mathrm{C}$ for 4 weeks and defrosting at room temperature. This figure shows the spectral transmissions of the lens immediately, $30 \mathrm{~min}$, and $1 \mathrm{~h}$ after defrosting, compared with the mean spectral transmission of the freshly extracted lenses.

Table 2. Total transmission in the visible spectrum (380-780 nm) of the freshly extracted pig crystalline lens and after being subjected to different storage methods

\begin{tabular}{lccccc}
\hline & $\begin{array}{c}\text { Freshly } \\
\text { slaughtered } \\
\text { pig lens }\end{array}$ & $\begin{array}{c}\text { In saline } \\
\text { sol. 24h }\end{array}$ & $\begin{array}{c}\text { In } \\
\text { formol } \\
\mathbf{2 4 h}\end{array}$ & $\begin{array}{c}\text { In } \\
\text { castor } \\
\text { oil }\end{array}$ & $\begin{array}{c}\text { Newly } \\
\text { defrosted after } \\
\text { 4 weeks frozen }\end{array}$ \\
\hline $\begin{array}{l}\text { Total } \\
\text { transmission }\end{array}$ & $94 \%$ & $83 \%$ & $68 \%$ & $81 \%$ & $94 \%$ \\
\hline
\end{tabular}

\section{DISCUSSION}

From the results obtained, it can be deduced that the spectral transmission, and therefore the transparency of the porcine crystalline lens, is affected by the storage method. The visible spectrum is the most affected, showing a direct effect on the transparency and consequently on the amount of light transmitted. This decrease is greater at shorter wavelengths and is particularly pronounced after storage in formalin, which reduced transparency by around $30 \%$ in the region of the visible spectrum, dropping to $40 \%$ for the $450 \mathrm{~nm}$ wavelength. Storage in saline solution and castor oil resulted in similar decreases in transparency, on the order of $10 \%$ in the visible spectrum. These results agree qualitatively with those from other studies ${ }^{(2,3)}$, although the studies analyzed human crystalline lenses preserved in castor oil. Additionally, only four wavelengths were investigated in these studies and a slight increase in absorption (decrease in transmission) was recorded over time. The differences in transmittance were not considered statistically significant for most wavelengths, but this may be because crystalline lenses of different ages were used. Another study reported differences in transmittance ${ }^{(17)}$ between crystalline lenses of different ages, finding that the absorption increases with age.

Storage by freezing at $-80^{\circ} \mathrm{C}$ for 4 weeks maintains the transparency of the crystalline lens. The spectral transmission measured immediately after defrosting at room temperature coincided exactly with that of the freshly extracted crystalline lens. However, if measurement was not performed until $30 \mathrm{~min}$ after defrosting, the spectral transmission decreased, with the total transmission in the visible spectrum decreasing from $94 \%$ to $89 \%$. The total transmission was $87 \%$ when the delay in measurement was $1 \mathrm{~h}$. The transparency of the crystalline lens decreased depending on the measurement delay. After an hour, the transparency of the frozen lens was still greater than that of the lens stored in saline solution and castor oil and certainly much greater than that of the lens stored in formalin. Figure 3 compares the spectral transmission of the pig crystalline lens according to the storage method. Differences can clearly be observed between the different storage methods. Likewise, table 2 summarizes the total transmission of visible light through the crystalline lens (transparency) depending on the storage method applied, quantifying the differences.

In conclusion, when determining the transparency of a crystalline lens, it is obviously better to measure the spectral transmission immediately after extraction. If this is not possible and the crystalline lens has to be stored, it is best to freeze it at $-80^{\circ} \mathrm{C}$, which will maintain the transparency for at least 4 weeks. The transmission spectrum should be measured immediately after defrosting at room temperature, which should yield practically the same result as that of the freshly extracted crystalline lens. If measurement is delayed after defrosting, the lens may gradually lose transparency. Storing the lens in saline solution or castor oil will result in a loss of transparency of approximately $10 \%$ after $24 \mathrm{~h}$. It is wholly inadvisable to store crystalline lens in formalin, because the transparency undergoes a severe decrease after $24 \mathrm{~h}$. This study used common pig crystalline lenses to ensure a large and homogeneous sample. Although the pig eye has been used as a model in numerous research studies, extending our results to human crystalline lenses must be addressed with the necessary precautions.

\section{REFERENCES}

1. Artigas JM, Felipe A, Navea A, Fandiño A, Artigas C. Spectral transmission of the human crystalline lens in adult and elderly persons: 
color and total transmission of visible light. Invest Ophthalmol Vis Sci. 2012;53(7):4076-84.

2. Weale RA. The post-mortem preservation of the transmissivity of the human crystalline lens. Exp Eye Res.1985;41(5):655-59.

3. Weale RA. Transparency and power of post-mortem human lenses: variations with age and sex. Exp Eye Res. 1983;36(5):731-41.

4. Said FS, Weale RA. The variation with age of the spectral transmissivity of the living human crystalline lens. Gerontologia. 1959; 3(4):213-31.

5. Olsen TW, Sanderson S, Feng X, Hubbard WC. Porcine sclera: thickness and surface area. Invest Ophthalmol Vis Sci. 2002;43(8): 2529-32.

6. Chandler M), Smith PJ, Samuelson DA, MacKay EO. Photoreceptor density of the domestic pig retina. Vet Ophthalmol. 1999;2(3):179-84.

7. McMenamin PG, Steptoe RJ. Normal anatomy of the aqueous humour outflow system in the domestic pig eye. J Anat. 1991; 178:65-77.

8. Vilupuru AS, Glaser A. Optical and biometrical relationships of the isolated pig crystalline lens. Ophthalmic Physiol Opt. 2001;21(4): 296-311.

9. Oriowo OM, Cullen AP, Chou BR, Sivak JG. Action spectrum and recovery for in vitro UV-induced cataract using whole lens. Invest Ophthalmol Vis Sci. 2001;42(11):2596-602.

10. Okuno T, Nakanishi-Ueda T, Ueda T, Yasuhara H, Koide R. Ultravio- let action spectrum for cell killing primary porcine lens epithelial cells. J Occup Health. 2012;54(3):81-6.

11. Artigas C, Navea A, López-Murcia MM, Felipe A, Desco C, Artigas JM. Spectral transmission of the pig lens: effect of ultraviolet $A+B$ radiation. J Fr Ophtalmol. 2014;37(10):773-9.

12. Artigas JM, Felipe A, Navea A, Artigas C, García-Domene MC. Spectral transmittance of intraocular lenses under natural and artificial illumination. Ophthalmology. 2011;118(1):3-8. Comment in: Ophthalmology. 2011; 118(11):2309-; author reply 2309-10. Ophthalmology. 2011;118(1):1-2.

13. Artigas JM, Felipe A, Navea A, Artigas C, Menzo JL. Ultraviolet radiation at Mediterranean latitudes and protection efficacy of intraocular lenses. J Fr Ophtalmol. 2013;36(1):23-8.

14. Artigas JM, Navea A, García-Domene MC, Artigas C, Lanzagorta A. Photoprotection and photoreception of intraocular lenses under xenon and white LED illumination. J Fr Ophtalmol. 2016; 39(5):421-7.

15. Artigas JM, Felipe A, Navea A, García-Domene MC, Pons A, Mataix J. Determination of scattering in intraocular lenses by spectrophotometric measurements. J Biomed Opt. 2014;19(12):127006.

16. Artigas JM, Capilla P, Felipe A, Pujol J. Óptica fisiológica. Psicofísica de la visión. Madrid: Interamericana McGraw-Hill; 1995.

17. Weale RA. Age and the transmittance of the human crystalline lens. J Physiol. 1988;395:577-87. 